\title{
Study on the Shanghai Old-age Social Security of Aging Time
}

\author{
Dengfeng Hua \& Yiyang Fan \\ Business School, University of Shanghai for Science and Technology \\ Shanghai 200090, China \\ E-mail: helen-hdf@126.com
}

The research is financed by the Innovation Fund Project for Graduate Student of Shanghai (No. JWCXSL0902). (Sponsoring information)

\begin{abstract}
With the advent of the aging time, old-age social security has a heavy burden. The current protection system consists of three aspects of old-age pension, health care and community services. There is still a big gap between the system and the need of the old society. Proposed the concept of old age service chain, and old age services of lifetime guarantee and after birth are incorporated into the system. The paper describes the experience of the United States and Taiwan area, and enlightenment for China to speed up the construction of old age security system.
\end{abstract}

Keywords: Aging, Service chain, Social security, Service after the death

At the end of 2008 , the population equal to and above 60 years old was 160 million, which occupied $12 \%$ of the total population (NBS, 2009), China is facing a serious population aging. A rapidly growing of aging Population, which brought the lifetime pension and health care needs and health needs after the funeral has brought great challenges to the society. The existing literature studied only during his lifetime pension, medical problems, however, little of service after birth. This paper unite service during the lifetime and after birth, and puts forward the concept of old age service chain and describes the experience of the United States and Taiwan area, and enlightenment for China to speed up the construction of old age security system.

\section{The Features of Aging in China}

General history of the development of China's population has experienced three stages. Before 1949, the country is in turbulent times, with times of hardship, population growth showed a high birth rate, high mortality and low growth characteristics of the population, the average life expectancy was 35 years old, and the population structure is of young model. Since 1949, national unity, economic and health levels have made great development, mortality has fallen markedly. population growth with high birth rate, low death rate and high growth characteristics of obvious characteristics of adult population structure; then reform and opening up, with the economy and the continued growth of medical standards, mortality further reduced, but As China's family planning policy of the strong implementation and change people's concept of fertility, the birth rate declining, the average life expectancy of population reached 70 years, Shanghai's number is 81 . At the end of 2008, the population equal to and above 60 years old was 160 million, which occupied $12 \%$ of the total population; China has entered the aging society.

China's aging population has three main features:

\subsection{The population aging is fast.}

43 years during 1964 to 2007 in China, the juvenile population of older-type cross-demographic structure completed, which from the adult to the old-type transformation only took 20 years, while the developed countries spent nearly a hundred years to complete on the same period.

\subsection{The huge number of aging population.}

Because of China's huge population, it is expected by 2020, China will have 167 million population over 65 years of age or older, accounting for about $24 \%$ of the world's aging population (Jian Zhang, 2005), the proportion or absolute number of China's aging population higher than the world average. 


\subsection{Aging is faster than the speed of economic development.}

Elderly dependency ratio increased year by year, from $6.4 \%$ in 1964 , and in 2002 to $11.6 \%$ and then to $2007,12.86 \%$, higher than China's GDP growth rate. United Kingdom, Sweden, Japan and other countries go into the aging time with 1-3 million U.S. dollars per capita GNP, while China enter the aging time in 2002, the per capita GNP is less than 1,000(Keiko Kitagawa, 2003).

\section{A service chain and the improvement of old age social security}

After hard working these years, China has basically set up social-oriented old-age security system covering urban and rural areas, which make everyone, enjoy the basic living security rights and interests. Shanghai implement the "basic security, wide coverage, multi-level, sustainable" guiding principles, after 20 years of effort, has been established security system, which adapt the level of economic development, coordinating urban and rural areas, covering all kinds of old-age for the crowd initially.

Shanghai old-age security system mainly consists of old-age insurance system, and other supplementary old-age security system. Old-age insurance system can be divided into two parts from the content, pension and health care, and from the provision of way, the system can be divided into the basic pension insurance and commercial pension insurance. Other supplementary old-age security system and focus on resolving the basic old-age insurance system are not included in the scope of protection of the difficult lives of the elderly. It includes cities and towns for senior citizens with no protection of basic old-age security for the elderly, the hardship grants of bereaved family, old-age pension after land acquisition, and old age pension for farmers, retired officers to settle pension.

However, an aging society not only brings the surge in the elderly population, as well as the rapid increase in the elderly population died each year. The death of a large number of the elderly population makes the burial site dropped sharply of China especially in Shanghai, and experts predict that, 30 years later, Shanghai will be no available funeral land. Worse, Shanghai has a large number of elderly people living alone, children don not live with them before his death, due to study, work, life and other reasons. No one is interested the large number of preparations, the etiquette, and the arrangements for the organization of the ceremony. Allow the elderly to live in security, or to die with dignity, which is a contents required by the harmonious society in China, and also an important part of people's livelihood security in an aging society.

The elderly needs in an aging society of the community is a chain-type, lifetime needs include the basic pension for the elderly needs, medical needs, accident protection needs, and the funeral service after the death. These four demand chain was arranged, this article defined it as an aging society demand chain (seen in Figure 1). And demand correspond to the services, services formed a chain, defined as the elderly community service chain. However, China's current service chain is not complete, there is pension corresponds to basic living needs, medical insurance correspond to medical needs, and accident insurance meets the needs of accident protection, but without products correspond to the needs of funeral services.

Life needed to plan, need to make early career planning. Preened contracts manifest of this "from start to finish" conception of death and the ultimate breadth of life care abroad.

\section{The experience and inspiration of preened funeral arrangement in The United States and Taiwan}

\subsection{The functions and features of preened funeral agreement in America and Taiwan region}

The American preened funeral agreement refers to prepare one's burial, which stresses the "contractual nature". Great service system contains services about the lives of senior citizens, legal, property, medical, psychological, and funeral form with all the related industries, creating an organic network of close cooperation. This is a powerful system combined the funeral services with medical, legal, social welfare, religious, and consulting together, and creates the ultimate all-round care service environment.

\section{Functions}

In the aging time, most old people need to rely on self-reliance from a life of self-care and the economy aspect of family, social welfare and convenience of the region. The preened funeral agreement can prepare for the funeral matters when the older are in economic self-sufficiency. The implementation of preened funeral agreement has three functions: Information sharing, Value clearing and Services Arrangements

\section{Features}

The American preened funeral agreement has the characteristics of the following aspects:

1) It has the responsibility to make explanation of contractual services for publicity.

2) Consumers can choose services and goods. They have the right to unilateral termination.

3) The wishes of customers should be respected. 
4) The price is clear and open. Fees are under preservation and safely operation.

\subsection{The experiences of the preened funeral agreement in America and Taiwan region}

The preened funeral agreement has been implemented for half a century in America, which has accumulated much experience.

(A) Promotion and the purchase of goods and services

In the United States, more than $43 \%$ of old people who above 50 have been introduced the preened funeral agreement of funeral. More than $39 \%$ of people over the age of 50 have received introduction about the preened funeral agreement of burial. In all purchased goods and services, cemetery at the highest proportion, accounting for $27 \%$, tombstone second, accounting for $18 \%$.

(B) The use of the fund

The fund of the preened funeral agreement collected is usually placed on the trustiest fund to invest in universal life insurance, the rate is up to $30 \%$, the proportion of Illinois also gets $28 \%$, and other types of investment accounts for $14 \%$.

(c) The specifications

U.S. states made quite big different transaction management standards of the preened funeral agreement. States have the different legal norms of consumers to purchase a cemetery deeds. For example, California allow the administrative costs of the trustee withdraw, but administrative costs not more than $4 \%$, Florida is not limited the amount of the provisions; on the termination of the trust, , the California provides consumers full contractual payments of the principal plus interest, subject to the deduction does not exceed $10 \%$ of the principal amount of administrative costs and to recover the costs, and in Florida, consumers can recover all principal within 30 days; Florida offers a variety of different investment channels, however, New York State don't allow investment; Florida also building consumer compensation fund to compensate for damage caused due to investment failure.

Taiwan has a hundred of Contract manufacturers, and mostly of them is small. Up to the end of 2004, the preened funeral agreement reached 10 million, accounting for 5\% of the total market; however, Taiwan still has much room for development compared with the life insurance (Wenlong Deng, Youzhi Huang, 2007; Youzhi Huang, 2002).

a) Consumer protection mechanisms are lack. The preened funeral agreement performance time is uncertainty, consumers the higher risk for the longer. Businesses closed down or unilaterally increase the protection of consumer rights when there are suitable arrangements.

b) Tips are unclear. Many websites prefer function promotion points as a lifetime contract finance and investment, but often after the signing of contracts, there will be greater awareness of performance gaps between the two sides. Taiwan does not have the provisions of the industry, and without at regular intervals to provide consumers with the latest changes.

c) There is no management oversight system. Without accompanying regulatory system, companies don't follow the agreed implementation easily, and this will show the adverse result of the industry. The need for official management of organizations has credibility.

d) No proper mechanism for compensation. In this way, the benefits of consumers are safeguarded. Taiwan has no corresponding mechanism.

\section{The inspiration}

(A) Conform to the aging requirements, Shanghai will be able to carry out appropriate

Overseas funeral services scheduled more and more common: Europe and the United States has more than 60 years of history, America have had the features of the SCI funeral chain, SUNLIFE in Japan as to the representative to carry out this business has more than 40 years, The number of customers in Canada participated in the business account for $25 \%$ of the total population, in Taiwan, it is growing rapidly in recent years. With the further acceleration of aging, Shanghai, as a high level of large cities, take the lead in carrying out this service is feasible. Detailed analysis is as follows:

1). China Life Insurance has great potential. Citizens began to focus on improving quality of life. They can complete their own choice in life and do the masters of their own lives, without causing financial burden on families. This reflects what the dying care for family members.

2). Shanghai aging society in line with the status quo. Shanghai is the highest degree of national aging cities, aging is also accelerated. Strengthen pension security is a major task in Shanghai. By the end of 2008, Shanghai's pure old family size and the number of older persons living alone, respectively, 863.8 thousand and 188 thousand people, the elderly dependency ratio in 2008 was $30.8 \%$ and in 2050 , the number is expected to reach $90.1 \%$. The serious situation of the aging prompted the matters relating to the old life become the focus of attention. 
3). Have a popular mandate. Aging products produced during his lifetime contract consumer groups, but also the next generation thinks about how to reduce family burden of life and the burial of previous generations. Longhua Funeral Parlor survey shows $18 \%$ of 300 people understand the preened agreements, more than $90 \%$ agree to conduct such business, and $25 \%$ of the people would buy. Education and income and is proportional to identity degree.

(B) Shanghai needs carried out in the form of insurance

Preened agreements prevalent in Europe and the United States, the key are its high degree of legal, industry management standards, the matured market. However, because of the funeral industry in Mainland China provides that "no pre-vault", lags behind the development of trust, influence, far less than insurance, and its capital management capabilities are limited, China is still difficult to fully use foreign trust model. Shanghai carry out such activities need meet several conditions: First, with approximate funeral service functions abroad; second, do not violate civil aspects of the country and financial policies; third, integration the community relations of consumers, enterprises and society; forth, the operation may be reality.

(C) Should learn from Taiwan's experience, legislative and regulatory ahead

According to the U.S. and Taiwan's experience, only establish a sound mechanism for consumer protection, professional arbitration body firstly, then guide enterprises to offer a clear presentation of products and services, can really give consumers freedom of choice.

\section{References}

Deng, Wenlong \& Huang, Youzhi. (2007). Analysis of Taiwan's preened agreement development. The Shanghai International funeral services Symposium Proceedings.

Huang, Youzhi. (2002). The studies on the preened funeral agreement management, No. 48.

Keiko Kitagawa. (2003). The last period of life issues and the preened agreement for senior citizens. Kyushu University Press, 277.

National Bureau of Statistics. (2009). China Statistical Yearbook 2009. Beijing: China Statistics Publishing.

Zhang, Jian. (2005). Filial piety and cultural challenges of population aging on the response to the theory of revelation. Chongqing: Southwest University for Nationalities, Vol. 26, 294-295.

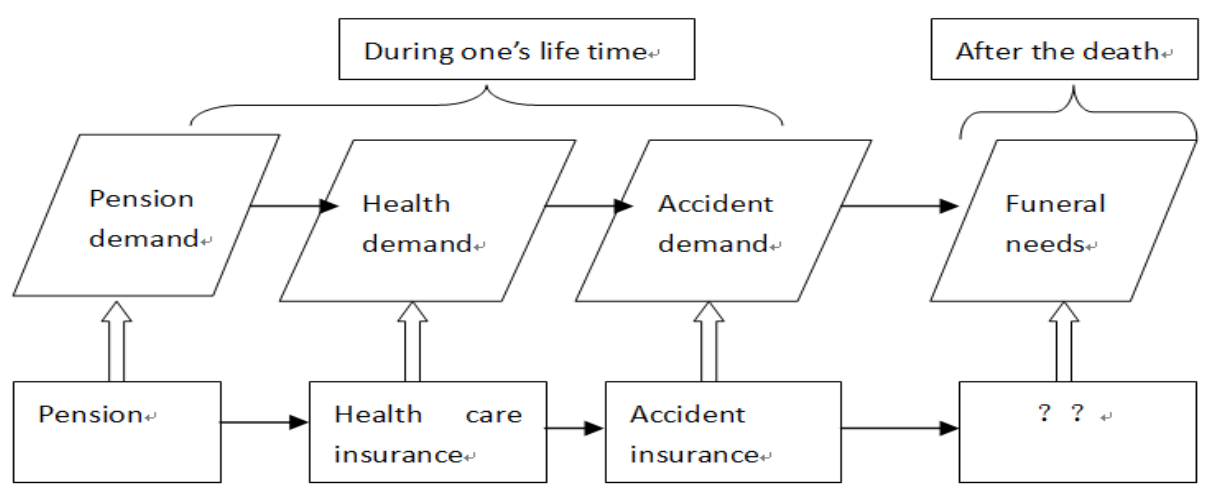

Figure 1. Service chain during the whole life 